\title{
Effect of dry cord care versus chlorhexidine cord care on cord separation time in healthy newborns: A comparative
} study

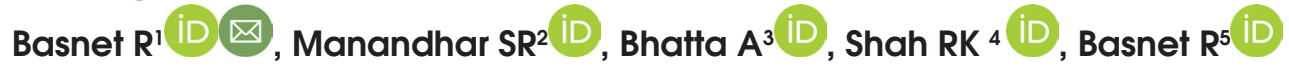

${ }^{1}$ Rydam Basnet, Lecturer; ${ }^{2}$ Sunil Raja Manandhar, Professor; ${ }^{3}$ Anwesh Bhatta, Assistant Professor; Department of Paediatrics, Kathmandu Medical College Teaching Hospital, Kathmandu, Nepal; ${ }^{4}$ Rakesh Kumar Shah, Medical Officer; Gajuri Primary Health Centre, Dhading Nepal. ${ }^{5}$ Ritika Basnet, Medical Officer; Manakamana Hospital Pvt. Ltd, Jhapa, Nepal.

\begin{abstract}
Background: Umbilical cord infection (omphalitis) is a major cause of neonatal mortality and morbidity in a developing country like Nepal. Detached umbilical stump is an important colonizing site for different types of bacteria and it also provides direct access to bloodstream. Hence, inadequate cord care may lead to omphalitis as well as neonatal sepsis. Objectives: This study aims to compare two different cord care regimens (dry cord care versus chlorhexidine cord care) on their cord separation time and the incidence of omphalitis.

Methodology: This is a comparative observational study conducted at the Neonatal unit of Kathmandu Medical College over a three months period (August 2019 to October 2019). All newborn babies born between 37 to 42 weeks of gestation were enrolled. Randomization for dry cord care and chlorhexidine cord care group was done via computer generated numbers. Statistical package for social sciences 19 version was used for statistical analysis.

Results: Among 514 term babies, 256 babies were included in the dry cord care group while 258 babies were enrolled in the chlorhexidine cord care group. The two groups had similar baseline characteristics. The mean cord separation time in the dry cord care group was $7.70 \pm 1.2$ days (range $3-15$ days), whereas in the chlorhexidine group, it was $7.77 \pm 1.4$ days (range 4-18 days).

Conclusion: There was no significant difference between the cord separation times in dry and chlorhexidine cord care regimens. Both dry cord care and chlorhexidine cord care regimens were found to be safe and effective.
\end{abstract}

Key words: Chlorhexidine cord care; Dry cord care; Omphalitis.

Access this article online

Website: www.jkmc.com.np

DOI: https://doi.org/10.3126/jkmc.v9i2.35523

HOW TO CITE

Basnet R, Manandhar SR, Bhatta A, Shah RK, Basnet R. Effect of dry cord care versus chlorhexidine cord care on cord separation time in healthy newborns: A comparative study. J Kathmandu Med Coll. 2020;9(2):70-3.

Address for correspondence

\section{Dr. Rydam Basnet}

Lecturer, Department of Paediatrics,

Kathmandu Medical College Teaching Hospital, Sinamangal, Kathmandu, Nepal.

E-mail: rydamb@gmail.com

Orcid ID: https://orcid.org/0000-0003-4576-3346

Copyright $\odot 2020$ Journal of Kathmandu Medical College (JKMC) ISSN: 2019-1785 (Print), 2091-1793 (Online)

\section{INTRODUCTION}

Teonatal sepsis remains a major cause of neonatal 1 mortality and morbidity in developing countries'. Nepal still has a high neonatal mortality rate of 21 per 1000 live births ${ }^{2}$. Umbilical cord infection (omphalitis) is a major cause of neonatal sepsis in Nepal and is linked to increased newborn deaths ${ }^{3}$. The umbilicus provides direct access to the bloodstream and is a fertile ground for bacterial growth. Inadequate cord care leads to local infections at the cord stump (omphalitis) or in the bloodstream (neonatal sepsis) ${ }^{4}$. The risk of umbilical infection increases until the umbilical stump detaches as the umbilical cord is an important colonizing site for different types of bacteria resulting in omphalitis ${ }^{5}$.

In order to prevent omphalitis, the World Health Organization (WHO) recommends clean, dry cord care in health facilities and at home in low neonatal mortality settings whereas chlorhexidine application over 
umbilical stump is recommended at home in areas with high neonatal mortality rate ${ }^{6}$.

This study aims to compare two different cord care regimens (dry cord care versus chlorhexidine cord care) on their cord separation time and incidence of omphalitis in these groups.

\section{METHODOLOGY}

This is a comparative observational study carried out in the Neonatal unit, Paediatrics Department of Kathmandu Medical College Teaching Hospital. This study was conducted over a three month period of August 2019 to October 2019. Ethical clearance was received from the Institutional Review Committee of Kathmandu Medical College (Ref: 080820110). Delivery rate of this tertiary hospital is around 400 per month and the Perinatal Mortality Rate (PMR) of this tertiary hospital is 10 per 1000 births and the Neonatal mortality rate (NMR) is 4.5 per 1000 live births ${ }^{7}$.

The study population consisted of healthy neonates born between 37 to 42 weeks of gestation at Kathmandu Medical College Teaching Hospital. Informed written consent was taken from the parents. Babies admitted to Neonatal Intensive Care Unit (NICU) and any babies with any umbilical disorder or requiring umbilical catheterization and lethal congenital malformations were excluded.

The eligible babies were randomized into two groups (dry cord care group and chlorhexidine care group) via computer generated random numbers. In group I (dry cord care group), after delivery of the baby, the umbilical cord was kept dry and nothing was applied. The diaper was folded below the umbilical stump, so that it would not irritate the umbilical stump.

In group II (chlorhexidine care group), chlorhexidine (4\% chlorhexidine gluconate gel) was applied on the umbilical cord by the following procedure ${ }^{8}$.

1. Washing hands properly with soap and water following six steps of proper hand washing.

2. Use of sharp protuberance of the lid to pierce the tip of the tube.

3. Before applying chlorhexidine, it was ensured that the baby is warm and is wrapped properly exposing only the naval area.

4. Chlorhexidine gel was applied immediately after cord cutting. Four percent chlorhexidine gel was applied on the umbilical stump and spread using the index finger around the abdominal area that comes in contact with the umbilical stump.
5. A single time application was done and waited for 2-3 minutes to make the gel dry.

In both the groups parents were counselled to avoid unhygienic cord care practices by the author.

\section{Sample Size Estimation}

Sample size was estimated using the formula

$N=Z^{2} \times P \times Q$
$D^{2}$

Where, $\mathrm{N}=$ Sample size, $\mathrm{Z}$ =at 95\% Confidence Interval $=1.96, \mathrm{P}=$ Prevalence of Omphalitis in previous study = $21 \% .{ }^{9}, \mathrm{Q}=1-\mathrm{P}, \mathrm{d}=$ error $=0.05$

Considering the non-response rate to be $10 \%$, Sample size was calculated to be 280 neonates on both dry cord care and chlorhexidine groups.

Personal data of the mother and the newborn's medical history reported in medical records were recorded in a proforma. A questionnaire was administered on regular neonatal follow up at a well-baby clinic or by phone at 15 days of life. A total of 256 babies were enrolled in the dry cord care group as 24 babies did not follow up and 258 babies were enrolled in the chlorhexidine group as 22 babies were lost to follow up.

Data were analysed in the Statistical package for social sciences (SPSS 19) version in the form of frequency, tables along with mean and standard deviation. Chi square and Mann Whitney tests were used for inferential statistics.

\section{RESULTS}

A total of 730 babies were delivered at Kathmandu Medical College Teaching Hospital over the three months period and 514 babies fulfilling the inclusion criteria were enrolled in this study. Among them 313 (60\%) were male babies.

The mean birth weight observed was $3057 \pm 443$ grams and the mean gestational age was $38.63 \pm 1.0$ weeks. Mean maternal age was 27.2 years.

The key clinical and epidemiologic features of the two study groups are shown in table 1. The two groups showed similar baseline characteristics.

As shown in table 2, the mean cord separation time in the dry cord care group was $7.70 \pm 1.2$ days; range was 3-15 days whereas in the chlorhexidine group it was $7.77 \pm 1.4$ days with the range of $4-18$ days. There 
Table 1: Comparison of basic demographics

\begin{tabular}{|c|c|c|c|}
\hline & Dry cord care group & Chlorhexidine group & p-value \\
\hline Number of participants & 256 & 258 & \\
\hline Birth Weight in grams (mean $\pm S D$ ) & $3048.75 \pm 453$ & $3066.78 \pm 434$ & 0.795 \\
\hline Gestational age at birth in weeks & $38.67 \pm 1.0$ & $38.59 \pm 1.0$ & 0.312 \\
\hline Male & $148(57.8 \%)$ & $165(64 \%)$ & \multirow{2}{*}{0.175} \\
\hline Female & $108(42.2 \%)$ & $93(36 \%)$ & \\
\hline Vaginal delivery & $101(39.5 \%)$ & $116(45 \%)$ & \multirow{2}{*}{0.212} \\
\hline Caesarean section & $155(60.5 \%)$ & $142(55 \%)$ & \\
\hline Maternal age (years) & $27.04 \pm 3.2$ & $27.44 \pm 3$ & 0.103 \\
\hline Primiparous & $139(54.3 \%)$ & $132(51.2 \%)$ & \multirow{2}{*}{0.481} \\
\hline Multiparous & $117(45.7 \%)$ & $126(48.8 \%)$ & \\
\hline
\end{tabular}

Table 2: Comparison of cord separation time and umbilical sepsis

\begin{tabular}{lccc}
\hline & Dry cord care & Chlorhexidine group & p-value \\
\hline Number & 256 & 258 & \\
\hline Cord separation in days & $7.70 \pm 1.2$ (range 3-15) & $7.77 \pm 1.4($ range $4-18)$ & 0.759 \\
\hline Omphalitis & 0 & 0 & 0 \\
Umbilical bleeding & 0 & 0 & \\
\hline
\end{tabular}

was no significant difference between these cord care regimens. Additionally, in this study, none of the newborns developed umbilical sepsis or had any umbilical bleeding.

\section{DISCUSSION}

This study compared the mean cord separation time in dry cord and chlorhexidine cord care group and the results showed the mean cord separation time in dry cord care group was 7.70 \pm 1.2 days with a range of 3-15 days whereas in chlorhexidine group it was $7.77 \pm 1.4$ days with a range of 4-18 days. Statistical analysis did not show significant difference in the cord separation between these standard regimens. The possible reason for not having significant difference was our better cord care handling practices in the tertiary hospital where the study was carried out.

In a study done by Mullany et al in Nepal and Bangladesh, the mean umbilical cord separation time in chlorhexidine group and dry cord care group was 6.5 days and 5.1 days respectively ${ }^{10}$, whereas in our study, the mean umbilical cord separation time was $7.77 \pm 1.4$ days (range 3-15 days) and 7.70 \pm 1.2 days (range 4-18 days) in chlorhexidine group and dry cord care group respectively. The difference in the cord separation time was perhaps secondary to multiple day chlorhexidine care regimen used by Mullany et al.
Kapellen et al did a randomized controlled study to compare efficacy and safety of chlorhexidine powder versus dry umbilical cord care of newborns. The observed cord separation time was 7 days in the chlorhexidine group and 7.8 days in the dry cord care group which was comparable to 7.70 and 7.77 days in our study respectively ${ }^{11}$.

In a study conducted by Maria et al in Spain, the mean cord separation time in the dry cord care group was 6.61 days compared to 7.70 days in our study. This study was conducted on newborns in public hospitals in Spain and our study was done on a tertiary care hospital in Nepal with different cord care protocols ${ }^{12}$.

According to a study in Southern Nepal omphalitis was identified in $5.5 \%$ of the newborns ${ }^{13}$. In our study, there were no cases of omphalitis. This is perhaps down to better facilities and proper cord handling practises in the tertiary hospital where the study was carried out.

\section{CONCLUSION}

The dry and chlorhexidine cord care regimens are most commonly used cord care regimens. There was no significant difference between the cord separation times in dry and chlorhexidine cord care regimens. Both dry cord care and chlorhexidine cord care regimens were found to be safe and effective. 


\section{ACKNOWLEDGEMENTS}

Our sincere thanks and acknowledgement to all the Pediatrics Department faculties, post-graduate residents and nursing staff to make this study successful. At last but not the least, our sincere gratitude and thanks goes

\section{REFERENCES}

1. Seale $A C$, Blencowe $H$, Manu AA, Nair $H$, Bahl $R$, Qazi SA, et al. Estimates of possible severe bacterial infection in neonates in sub-Saharan Africa, south Asia, and Latin America for 2012: a systematic review and meta-analysis. Lancet Infect Dis. 2014 Aug;14(8):731-41.[PubMed | Full Text|DOI]

2. Population division, Ministry of Health and Population (MOHP), Government of Nepal. Infant and child mortality. In: New ERA and Macro International Inc. eds. Nepal Demographic and Health Survey (NDHS) 2016. Kathmandu: Ministry of Health and Population, New ERA, and Macro International Inc; 2016. 142p. [Full Text]

3. Mullany LC, Darmstadt GL, Katz J, Khatry SK, Leclerq SC, Adhikari RK, et al. Risk of mortality subsequent to umbilical cord infection among newborns of southern Nepal: cord infection and mortality. Pediatr Infect Dis J. 2009 Jan;28(1):17-20. [PubMed | Full Text |DOI]

4. Stewart D, Benitz W, COMMITTEE ON FETUS AND NEWBORN. Umbilical Cord Care in the Newborn Infant. Pediatrics. 2016 Sep;138(3):e20162149. [PubMed | Full Text |DOI]

5. Güvenç $H$, Aygün $A D$, Yaşar $F$, Soylu $F$, Güvenç M, Kocabay K. Omphalitis in term and preterm appropriate for gestational age and small for gestational age infants. J Trop Pediatr. 1997 Dec;43(6):368-72. [Full Text |DOI]

6. World Health Organization. WHO recommendations on postnatal care of the mother and newborn. World Health Organization; 2014. [Full Text]

7. Manandhar SR. Outcome of surfactant replacement therapy in preterm babies with hyaline membrane disease at neonatal intensive care unit of a tertiary to all the neonates and their parents, without whom this research would not be possible.

Conflict of interest: None

Source(s) of support: None hospital. Birat Journal of Health Sciences. 2018; 3(3):486-8.[Full Text | DOI]

8. Department of Health, Government of Sindh. Role of $7.1 \%$ chlorhexidine digluconate in prevention of Neonatal Sepsis. Department of Health, Government of Sindh; 2014. [Full Text]

9. Mir F, Tikmani SS, Shakoor S, Warraich HJ, Sultana S, Ali SA, et al. Incidence and etiology of omphalitis in Pakistan: a community-based cohort study. J Infect Dev Ctries. 2011 Dec 13;5(12):828-33. [PubMed|Full Text | DOI]

10. Mullany LC, Arifeen SE, Khatry SK, Katz J, Shah $\mathrm{R}$, Baqui $\mathrm{AH}$, et al. Impact of Chlorhexidine Cord Cleansing on Mortality, Omphalitis and Cord Separation Time Among Facility-Born Babies in Nepal and Bangladesh. Pediatr Infect Dis J. 2017 Oct;36(10):1011-3.[PubMed | Full Text| DOI]

11. Kapellen TM, Gebauer CM, Brosteanu O, Labitzke B, Vogtmann C, Kiess W. Higher rate of cord-related adverse events in neonates with dry umbilical cord care compared to chlorhexidine powder. Results of a randomized controlled study to compare efficacy and safety of chlorhexidine powder versus dry care in umbilical cord care of the newborn. Neonatology. 2009;96(1):13-8. [PubMed |DOI]

12. López-Medina MD, López-Araque $A B$, Linares-Abad M, López-Medina IM. Umbilical cord separation time, predictors and healing complications in newborns with dry care. PLoS One. 2020 Jan 10;15(1):e0227209.[PubMed |Full Text |DOI]

13. Mullany LC, Darmstadt GL, Katz J, Khatry SK, LeClerq SC, Adhikari RK, et al. Risk factors for umbilical cord infection among newborns of southern Nepal. Am J Epidemiol. 2007 Jan 15;165(2):203-11. [PubMed | Full Text| DOI ] 